\title{
A COSMOgonia POÉtica de HiLda HiLST
}

\author{
Andréa Jamilly Rodrigues Leitão* \\ UFPA \\ andreajamilly@gmail.com
}

Antônio Máximo Ferraz ${ }^{* *}$

UFPA

profmaximoferraz@gmail.com

RESUMO: O presente trabalho pretende explorar a experiência literária de Hilda Hilst a partir da noção de cosmogonia, tendo em vista a leitura do poema "Amavisse", da obra homônima de 1989. A cosmogonia poética engendra-se na passagem da escuridão à claridade, da abertura caótica do fundo desconhecido das coisas ao acontecer luminoso das formas e dos sentidos. Em toda a sua pujança carnal, a escrita hilstiana é marcada pelo excesso, pela desmesura verbal, pelo transbordamento dos limites, pela renúncia às medidas. No poema em estudo, a referência à imensidão e à volúpia da noite torna-se, por excelência, metáfora para o processo criativo. O grande corpo da poesia é fecundado na carnalidade da noite para dar à luz a palavra. O erotismo, o qual perpassa fundamentalmente a obra da poeta paulista, remonta à dinâmica da transgressão dos interditos, entendida de acordo com os pressupostos teóricos de Bataille (1987). Na sua poética transgressora, colocam-se em tensão a vida e a morte, o divino e o humano, o verbal e o carnal, o ventre luzente da criação e a noite pulsante das formas.

Palavras-chave: Cosmogonia poética. Escrita. Transgressão.

* Mestre em Estudos Literários pelo Programa de Pós-Graduação em Letras da Universidade Federal do Pará (UFPA).

** Professor Adjunto do Programa de Pós-Graduação em Letras da Universidade Federal do Pará (UFPA). 
ABSTRACT: This paper intends to explore the literary experience of Hilda Hilst from the notion of cosmogony, with a view to reading the poem "Amavisse" of the homonymous book (1989). The poetic cosmogony is engendered in the passage from darkness the clarity, the chaotic opening of the unknown to the bottom of things happen luminous shapes and directions. In all its carnal strength, the hilstiana writing is marked by excess, the verbal excesses, overflowing the limits, the renunciation of action. In the poem study, the reference to the immensity and the voluptuousness of the night becomes, par excellence, a metaphor for the creative process. The large body of poetry is fertilized in the night carnality to give birth to the word. Eroticism, which basically runs through the work of the Brazilian poet, dating back to the transgression of the dynamics of prohibitions, approved in agreement with the theoretical assumptions of Bataille (1987). In its transgressive poetic, puts in tension the life and death, the divine and the human, the verbal and the carnal, the shining womb of creation and the pulsating night of forms.

Keywords: Poetic cosmogony. Writing. Transgression.

\section{Considerações iniciais}

Este trabalho visa à interpretação da escrita literária e sua correlação com a dimensão cosmogônica da criação poética, configurada na realização literária de Hilda Hilst (1930-2004), a partir da leitura do poema "Amavisse", da obra homônima de 1989. Na edição consultada ${ }^{20}$, essa obra da escritora paulista compõe o volume intitulado Do desejo - publicado originalmente pela editora Pontes, em 1992 -, cujo conjunto total conta com sete livros integrais. São eles, respectivamente: Do desejo e Da noite, que são inéditos; Amavisse, Via espessa e Via vazia, que estão reunidos na obra Amavisse; Alcoólicas (1990) e Sobre a tua grande face (1986).

A noção de cosmogonia, pertencente à esfera do sagrado, é apropriada como chave de leitura para melhor compreender o advento

${ }^{20}$ A edição consultada neste trabalho foi publicada pela editora Globo, em 2004, e organizada pelo professor Alcir Pécora. 
impetuoso do tecido poético presente nos poemas de Hilda Hilst. O processo da escrita surge em toda a sua pujança carnal, atravessada essencialmente pela volúpia do excesso, pelo transbordamento dos limites. Em meio ao jogo de luzes e sombras que concorrem para a emergência transgressora da palavra, as imagens presentes em "Amavisse" remetem ao descomedimento absoluto do verbo, à vastidão caótica e indefinível das formas inominadas, ao fundo obscuro e silencioso das coisas, ao abismo infinito que cada ser humano traz em si.

O fazer poético e a encenação dos corpos amantes encontram-se intimamente associados, conjugando-se em uma unidade. Conforme observa Nelly Novaes Coelho (1980, p. 276), "o mistério da Poesia e o do Amor foram, desde as primeiras horas, os polos imantados que atraíram e fecundaram a invenção da palavra em Hilda Hilst". Ideia reforçada no seguinte verso do poema "Do desejo", da obra homônima: "Desejo é uma palavra com a vivez do sangue" (HILST, 2004, p. 24). A escrita de matizes notavelmente eróticos da poeta remonta à dinâmica da transgressão, entendida de acordo com os pressupostos teóricos de Georges Bataille (1987). No seu vigor poético de transgredir as restrições e de subverter os padrões tradicionais, o poema "Amavisse" recupera a tensão entre a vida e a morte, o verbal e o carnal, o sagrado e o profano, o ventre luzente da criação e a noite pulsante das formas.

\section{As insinuações do erotismo: a palavra transgressora hilstiana}

O poema "Amavisse" divide-se em vinte segmentos, indicados por números romanos. O título faz referência a Vladimir Jankélévitch, filósofo e musicólogo francês, presente na epígrafe da obra: "ter um dia amado (amavisse)". A forma latina comunica a ausência do ser 
amado ou, em outro plano, a fugacidade do amor, já que este está sempre lançado pela dimensão temporal. Nas "barcaças do Tempo" que fluem incessantemente, os amantes consumam o enlace de seus corpos na brevidade pungente do instante amoroso. No contexto geral da obra de Hilda Hilst, o termo amavisse recupera, sobretudo, a nostalgia do princípio originário das coisas. Há, ao longo dos poemas, a busca intensa pela "primitiva urna de palavras", cuja força propulsora propaga a "fonte do meu primeiro grito" e as suas possibilidades criativas, como observam os versos do segmento "VI" de "Amavisse" (HILST, 2004, p. 47).

Nesse sentido, a cosmogonia é um fenômeno do domínio do sagrado que diz respeito à manifestação de todo e qualquer exercício de criação. Em linhas gerais, empreende a passagem do caos ao cosmos, isto é, do caos diante do informe, do inominável, da palavra ainda não revelada, para o desabrochar poético da criação. É no próprio percurso da criação que o Verbo, surgindo do "caos" originário, vai sendo anunciado, ordenado e conquistado. Nesse contexto, o poeta é a entidade que "vai assumir a responsabilidade da tarefa nomeadora atribuída à Poesia" (COELHO, 1980, p. 275). Já o termo "poético" refere-se ao sentido originário de póiesis, que, etimologicamente, significa um "produzir que dá forma, um fabricar que engendra, uma criação que organiza, ordena e instaura uma realidade nova, um ser" (NUNES, 2003, p. 20). Em outros termos, alude ao próprio processo de construção de sentidos de uma obra de arte.

A cosmogonia poética entretecida nos versos de "Amavisse", como uma grande noite voluptuosa, concebe uma escritura marcada pelo excesso, pelo desregramento, pela desmesura, pelo transbordamento vertiginoso das palavras ou, para lembrar o termo utilizado por Eliane Robert Moraes (1999), pelo “estilhaçamento”. Daí a referência significativa à noite e sua vastidão irredutível como 
metáfora da criação poética no poema supracitado de Hilda Hilst, na medida em que a seara noturna evoca a abertura abissal para o caótico, a dissolução ilimitada das formas, a ebriedade dionisíaca, a explosão do transe erótico e o furor arrebatador das paixões humanas.

$\mathrm{Na}$ poética hilstiana, a dimensão do erotismo perpassa o envolvimento carnal dos amantes e, ao mesmo tempo, a própria concepção de escrita. Pois, para empregar uma imagem presente em "Amavisse", "o poeta [é aquele que] habita nas ardências" (HILST, 2004, p. 48). Na sua obra intitulada O erotismo, Georges Bataille compreende a manifestação erótica como uma experiência humana interior, uma vez que diz respeito ao seu próprio modo de ser, à sua própria condição de realização no mundo. A experiência instaurada pelo erotismo concretiza-se no jogo entre o interdito e a transgressão. De acordo com o escritor francês, "o interdito e a transgressão respondem a esses dois movimentos contraditórios: o interdito intimida, mas a fascinação introduz a transgressão" (BATAILLE, 1987, p. 64). Toda interdição impõe um limite, uma restrição, um obstáculo, um impedimento, uma impossibilidade. O fascínio que incorre sobre a interdição, ao "intimidar", conduz necessariamente ao ato pelo qual se possa transgredi-lo. José Paulo Paes (2006, p. 17) resume essa dinâmica aludida por Bataille como um "jogo dialético entre a consciência do interdito e o empenho de transgredi-lo [que] configura a mecânica do prazer erótico".

A importância do erotismo reside justamente na experiência de suscitar o fascínio de romper com os limites demarcados e, por conseguinte, de superar as interdições. Diante disso, Bataille (1987, p. 16) observa que "essencialmente, o domínio do erotismo é o domínio da violência, o domínio da violação", seja diante dos interditos prescritos, seja diante da finitude humana. Esse processo de 
"violência" opera uma fissura, ou melhor, uma abertura ilimitada para a plenificação do impulso desejante, da realização erótico-carnal. Ao corpo, quando encaminhado a uma experiência de liberação erótica, é facultada a possibilidade de subverter as normas vigentes. Pois, o movimento de transgressão produz a consagração do êxtase e da volúpia ou, nas palavras do filósofo, "a experiência leva à transgressão realizada, à transgressão bem-sucedida que, sustentando o interdito, sustenta-o para dele tirar prazer" (BATAILLE, 1987, p. 36, grifo do autor).

A própria noção de cosmogonia já remonta à transgressão. Na sua vigência prenhe de fecundidade, o movimento cosmogônico da criação possibilita "violar", isto é, romper com a opacidade do verbo em direção à conquista da expressão da matéria poética, ou melhor, da palavra transgressora como "fonte do meu primeiro grito". $\mathrm{Na}$ contracapa da primeira edição da obra Amavisse, publicada pela editora Massao Ohno, o "escritor e seus múltiplos" são reconhecidos no papel de transgressores por excelência. Dizem os versos:

Depois, transgressor metalescente de percursos Colou-se à compaixão, abismos e à sua própria sombra.

O poeta cumpre o ímpeto erótico de transgredir os "abismos" e a "sua própria sombra", de modo que compete às experiências radicais feitas no "extremo-tudo" da palavra o esforço de desagregar-se e de (re)fundar-se originalmente a cada novo instante criativo. Conforme destaca Bataille (1987, p. 18), “o que está em jogo no erotismo é sempre uma dissolução das formas constituídas". Nesse sentido, a noite configura-se como o espaço privilegiado onde há simultaneamente a "dissolução" e a fermentação das formas. Como exprimem os versos de "Sonetos que não são", em Roteiro do silêncio 
(1959): "Tenho medo de ti e deste amor/ Que à noite se transforma em verso e rima" (HILST, 1980, p. 259). Se, por um lado, o elemento da noite gera o fascínio diante da liberdade e da efervescência de possibilidades criativas entre "versos e rimas", como uma maneira de transgredir a escuridão impassível e indeterminada; por outro, revela o "medo", o desamparo humano em meio ao desconhecido da demanda amorosa e do próprio humano.

Nesse terreno de indefinição e de sondagem de novos caminhos, a obra de Hilda Hilst rompe com os paradigmas tradicionais, infringe os domínios da interdição, inclusive em torno da questão do sagrado, instaurando a profanação - como marca essencial do ato de transgressão - ou, ainda, a "subversão entre o alto e o baixo" (MORAES, 1999, p. 120). A começar pela ruptura com a rigidez dogmática que paira sobre o plano divino a fim de conferir-lhe uma faceta soberanamente humana e carnal, cujos efeitos espraiam-se para o âmbito da poesia. No preâmbulo do poema "Amavisse", Deus é referido como o "senhor de porcos e de homens", e há, ainda, a alusão à figura do criador como o "Porco-poeta", o qual se encontra "na cegueira, no charco/ à espera da Tua Fome". Assim, desmascara-se a aura excelsa de idealização em torno da criação poética no afã de aproximá-la, sob uma perspectiva profundamente carnal, do "verbo amar", a saber, daquele que "sangra, estilhaça, devora" (HILST, 2004, p. 41). Na figura do porco, animal cuja pele rósea se aproxima à pele do humano, e que se costuma associar à sujeira, opera-se a subversão de um erotismo idealizado por uma sacralidade puritana, dicotomicamente separada da dimensão profana. A poética hilstiana, ao fazer o sagrado e o profano comungarem, eleva o sacrilégio à expressão intensificada da sacralidade, pois a profanação - como na associação entre Deus e porco - é o reconhecimento, por efeito de 
contraste máximo, da dimensão carnalmente sagrada do erotismo. Não à toa, a obscenidade se apresenta com muito vigor na poética de Hilda Hilst. Na obra Estar sendo. Ter sido (1997), destaca-se, paralelamente, a personagem do "Poeta-mula".

Comentando casos particulares da prosa de Hilda Hilst - mas a reflexão pode ser estendida para pensar o conjunto da sua obra -, Eliane Robert Moraes (1999, p. 117) afirma que, "ao confrontar sua metafísica do puro e do imaterial com o reino do perecível e do contingente que constitui a vida de todos nós, a escritora excede a sua própria medida". Desse modo, a escrita desmedida de Hilda Hilst promove um significativo deslocamento, com o desmantelamento da hierarquização entre domínios até então entendidos dentro de uma tradição de cunho judaico-cristã como inconciliáveis, colocando-se em tensão o sagrado e o profano, o eterno e o efêmero, a vida e a morte, o sublime e o grotesco, o verbal e o carnal.

No poema "Do desejo", da obra homônima, questiona-se justamente a espécie de interdição que paira sobre a possibilidade de inserção da dimensão carnal, transitória e perecível no território da poesia:

Por que não posso

Pontilhar de inocência e poesia

Ossos, sangue, carne, o agora

E tudo isso em nós que se fará disforme?

(HILST, 2004, p. 20).

O poema, então, indaga-se e lança-se à procura de um canto que poderá a um só tempo abranger o exercício humano de estar sendo e a concretude da sua manifestação amorosa e, simultaneamente, o que é eterno e irredutível à experiência, ou seja, o que é velado à condição humana, como se pode reconhecer nos versos do poema "Da noite", da mesma obra: 
Que canto há de cantar o que perdura?

A sombra, o sonho, o labirinto, o caos

A vertigem de ser, a asa, o grito. [...]

Que canto há de cantar o indefinível?

$\mathrm{O}$ toque sem tocar, o olhar sem ver

A alma, amor, entrelaçada dos indescritíveis.

Como te amar, sem nunca merecer?

(HILST, 2004, p. 30).

Surge uma escrita, ou melhor, um "canto" transgressivo, no qual se inscreve tudo aquilo que renuncia à medida, fazendo cintilar a sofreguidão da vida: "a sombra, o sonho, o labirinto, o caos/ a vertigem de ser, a asa, o grito". Poesia que apela aos excessos do "indefinível" e dos contornos "indescritíveis", ou, nos termos de Bataille, ao que transcende a precisão dos limites e a submissão à ordem estabelecida, cujo imperativo reside em segregar em polos opostos corpo e alma, tangível e intangível, carne e poesia. Para o filósofo francês, a essência do erotismo encontra-se dentro de um trânsito incessante entre a transgressão e a superação dos interditos. Diante disso, vislumbra-se em Hilda Hilst uma escrita que pretende reunir, em um diapasão eminentemente erótico, palavra e carnalidade. Octavio Paz (1994, p. 12) revela uma forte ligação entre o erotismo e a poesia, chegando a exprimir, por meio de sua genuína veia literária, que "o primeiro é uma poética corporal e a segunda, uma erótica verbal".

A "poética corporal" da escritora entrega-se à liberdade vigente na chama erótica dos amantes, uma vez que contribui com o seu fulgor pleno para a fruição dos seus corpos e a explosão extática da palavra. Como bem sinalizam os seguintes versos de "Via espessa":

Por que não deixas o fogo onividente 
Lamber o corpo e a escrita? E por que não arder

Casando o Onisciente à tua vida?

(HILST, 2004, p. 76).

Sob a chave da "erótica verbal", o "corpo" e a "escrita" se amalgamam ao serem acometidos pelo lume lascivo do "fogo onividente", dissolvendo "ardentemente" as fronteiras entre o "Onisciente" e a "vida" na composição da obra de arte. Eis a celebração do élan subversivo relacionado imageticamente com o desafio lançado aos deuses pelo fogo prometeico. Com efeito, implica a transgressão maior, a saber, a provocação aos anseios metafísicos, ao consagrar a união entre o divino e o humano, entre a poesia e a existência.

\section{Da noite à palavra: a escrita cosmogônica de Hilda Hilst}

O segmento "XIX" do poema "Amavisse" encena, em termos metalinguísticos, o processo de criação poética. $\mathrm{O}$ gesto de compor tessituras e o jogo amoroso entre os corpos realizam-se à luz de uma verdadeira cosmogonia poética. Segue abaixo o poema na íntegra:

Empoçada de instantes, cresce a noite

Descosendo as falas. Um poema entre-muros

Quer nascer, de carne jubilosa

E longo corpo escuro. Pergunto-me

Se a perfeição não seria o não dizer

E deixar aquietadas as palavras

Nos noturnos desvãos. Um poema pulsante

Ainda que imperfeito quer nascer.

Estendo sobre a mesa o grande corpo

Revista Texto Poético | ISSN: 1808-5385 | Vol. 20 (1o sem-2016) - p. 177 
Envolto na sua bruma. Expiro amor e ar

Sobre as suas ventas. Nasce intensa

E luzente a minha cria

No azulecer da tinta e do dia.

(HILST, 2004, p. 60).

A noite, em sua gestação demiúrgica, é fonte misteriosa de toda criação, urdidura poética, "descosendo as falas". E isso na medida em que, de acordo com o verso do poema "Do desejo", a "noite é o velado coração de Deus" (HILST, 2004, p. 21). O poema rompe as densas trevas do incriado e o invólucro silencioso ao trazer a lume o seu corpo verbal de sentidos. Ou melhor, transgride a interdição sugerida pela posição de "entre-muros". Esse movimento de sobrepor-se aos cerceamentos remete à imagem do "Pássaro-Poesia", presente no primeiro segmento que inicia o poema "Amavisse", o qual sobrevoa livremente "o Amanhã, a luz, o impossível". A partir do qual o canto que, sem medida, atravessa os limites e atinge os avessos não somente da criação como da própria existência do ser humano:

Só canto a ti

Pássaro-Poesia

E a paisagem-limite: o fosso, o extremo

A convulsão do Homem

(HILST, 2004, p. 42).

Qual o limite da linguagem senão o silêncio? O "não dizer" está sempre à espreita do ato de criação, como sugerem os versos de "É tempo de parar as confidências", de Roteiro do silêncio: "Meu roteiro de silêncio./ Minha vida de poesia" (HILST, 1980, p. 252). O poeta atravessa os "noturnos desvãos" em meio à abertura abissal e 
vertiginosa de uma cegueira silenciosa ${ }^{21}$, na qual todo o potencial criativo se manifesta em estado de latência na "primitiva urna de palavras". Tal como também aludem os versos do segmento "VI", do poema "Amavisse":

Que me devolvam a noite, o espaço

De me sentir tão vasta e pertencida

(HILST, 2004, p. 47).

No célebre poema "O lutador", de Carlos Drummond de Andrade - publicado originalmente na obra José (1942) -, é possível identificar a associação entre o combate corpo a corpo com a palavra e o mistério impenetrável da noite, como se pode observar nos versos da estrofe final:

O teu rosto belo, ó palavra, esplende na curva da noite que toda me envolve.

Tamanha paixão e nenhum pecúlio. Cerradas as portas, a luta prossegue nas ruas do sono.

(ANDRADE, 2000, p. 185).

A palavra encontra o seu refúgio no fulgor noturno que "envolve" e consome tanto a realização da obra poética quanto o seu criador. $\mathrm{O}$ poeta-lutador, em sua "tamanha paixão e nenhum pecúlio", empreende

${ }^{21}$ Expressão retirada do romance $A$ obscena senhora $D$ (1982). Segue o trecho na íntegra, no qual a personagem-narradora Hillé afirma: "eu Nada, eu nome de Ninguém, eu à procura da luz numa cegueira silenciosa” (HILST, 2001, p. 77).

Revista Texto Poético I ISSN: 1808-5385 | Vol. 20 (1o sem-2016) - p. 179 
a sua vã e difícil peregrinação em busca da captura da expressão verbal, desafiando-se na imensidão da "curva da noite". Mergulhado em uma espécie de limbo da criação, a ele "cabe a tarefa nomeadora: a da palavra demiúrgica que cria o Real" (COELHO, 1999, p. 67, grifo do autor). Ao abrigar em si a promessa da linguagem, a grandeza do ofício de que se investe o poeta reside em evocar a "palavra demiúrgica", maturá-la para, enfim, fazer rebentar a obscuridade do seio do inominável e operar novos mundos. À semelhança de um manifesto poético, é possível encontrar o culto ao fazer da poesia nos versos do poema "Iniciação do poeta", incluído na obra Trajetória poética do ser (1963-1966):

Vede minha voz: a cada dia se faz clara.

Pastor e guardião

Pasce e resguarda a minha fala

E o que é palavra rompe

A lúcida matéria onde se esconde.

(HILST, 1980, p. 181).

Como já foi dito anteriormente, o fenômeno da cosmogonia, compreendido como a passagem do Caos ao Cosmos, consiste na manifestação sagrada propulsora do exercício de toda e qualquer criação. Em outros termos, é capaz de instaurar realidades de sentido, as quais, por si sós, restituem a unidade primordial e a sacralidade originária do mundo. De acordo com Mircea Eliade (1972, p. 34), a cosmogonia "constitui o modelo exemplar de toda situação criadora: tudo que o homem faz repete, de certa forma, o 'feito' por excelência, o gesto arquetípico do Deus criador: a Criação do Mundo”. Nesse sentido, a cosmogonia está intimamente interligada à origem mítica da 
Criação, e a palavra, por sua vez, ao Verbo Divino ${ }^{22}$. No Gênesis, a linguagem é a instância sagrada por meio da qual Deus concretiza o Seu poder de Criação. No simples enunciar da palavra, o mundo se constitui em sua totalidade plena: "Disse Deus: Faça-se a luz; e foi feita a luz" (BÍBLIA, 2010, p. 3). Dentro da tradição literária, A Divina Comédia, de Dante Alighieri, associa a imagem de Deus à amplidão da Prima Luz, cujo clarão é tão intenso que, embora a capacidade de visão do poeta seja desafiada, Dante deixa-se arrebatar pela sua chama vivaz: "Ó Farta Graça, por quem incidir/ ousei os olhos meus na Luz Eterna,/ tão fundo até nela me consumir!" (ALIGHIERI, 2009, p. 728).

No poema de Hilda Hilst, por sua vez, a cosmogonia ganha contornos eróticos ao funcionar como uma metáfora para o gesto fecundo do corpo humano em dar à luz um rebento e, em outra dimensão, para a vigência da instância criativa. Na medida em que o "poema pulsante" deseja "nascer", vir à tona, sob o claro-escuro da experiência cosmogônica, à semelhança da vida que se gesta no ventre carnal. Em "Via espessa", há também a referência a essa inter-relação entre o exercício de criação da obra de arte e a própria existência:

Da carne de mulheres, querem nascer os homens.

E o poeta preexiste, entre a luz e o sem-nome

(HILST, 2004, p. 65).

Nesse entrelugar, entre o nome e o "sem-nome", o homem tensiona os limites do nomear ou do definir aquilo que excede a sua capacidade de compreensão. O poema "Amavisse" concebe, sob o limiar do não dizer, o "parto" da carnalidade da noite, "empoçada de instantes". Por assumir a temporalidade de um corpo que nasce - logo,

${ }^{22}$ No livro de João $(1,1)$, está escrito o seguinte: "No princípio era o Verbo, e o Verbo estava com Deus, e o Verbo era Deus" (BÍBLIA, 2010, p. 948).

Revista Texto Poético | ISSN: 1808-5385 | Vol. 20 (1o sem-2016) - p. 181 
marcado pela transitoriedade e pela finitude -, a escrita constitui-se como um processo "imperfeito", inacabado e sempre por se fazer. Mas é justamente nessa circularidade que "tecida de carmim no traçado das horas/ A vida se refaz" (HILST, 2004, p. 56). A poesia, por extensão, plenifica-se criativamente em toda a sua dimensão inesgotável.

O desejo, como uma espécie de fome, palpita e acomete o "grande corpo" da criação, é disposto sobre a "mesa", enquanto alimento para nutrir a palavra poética. Como ressaltam os versos do poema " $\mathrm{Da}$ noite", na obra Do desejo, em cujo apelo dirigido ao amante reside a satisfação da "noite de fomes", grávida de potencialidades criativas noite que se confunde com a fecundidade dos corpos durante a comunhão amorosa:

Que te demores

Cobrindo-me de sumos e tintas

$\mathrm{Na}$ minha noite de fomes

(HILST, 2004, p. 38).

O poema "Amavisse" personifica a poesia na imagem do "PássaroPoesia" que, com a leveza de seu adejar, dispõe os caminhos da criação. Mas, para que isso ocorra, é preciso atingir uma condição: "Expiro amore ar/ Sobre suas ventas". Em outras palavras, é necessário recobrar a volúpia que impulsiona a potência criativa de Eros, como a semente que fecunda o grande corpo da poesia. Pois, a energia proveniente de Eros, enquanto força potencialmente criativa, impele a dimensão erótica, assim como a do fazer poético. Para empregar a imagem de Safo de Lesbos, Eros constitui um "tecelão de mitos"23, um artífice da linguagem.

${ }^{23}$ Verso pertencente ao fragmento 19 (LESBOS, 2003, p. 53).

Revista Texto Poético I ISSN: 1808-5385 | Vol. 20 (1o sem-2016) - p. 182 
O "corpo de luz" do Pássaro-Poesia opera o desvendamento essencial da obra, a saber, a parição da "carne jubilosa", a qual está sendo gestada no ventre poético: "Nasce intensa/ E luzente a minha cria/ No azulecer da tinta e à luz do dia". Partindo das trevas do desconhecido, do limiar dos "grossos muros", dos abismos do "sinistro Nada", o poema ganha contornos corpóreos no "azulecer da tinta" do traçado verbal e desponta do obscuro horizonte em plena "luz do dia". No poema "Do desejo", a criação da obra de arte é comparada, de modo similar, ao nascimento de um ser poético, ao despertar do súbito clarão de um "dia magnânimo", ao solário que acolhe o "amanhecer" das palavras:

Como se fosse nascer

E tu fosses o dia magnânimo

Eu te sorvo extremada à luz do amanhecer.

(HILST, 2004, p. 19).

Para a poética de Hilda Hilst, o compromisso de criar reside em encarar a tensão entre Eros e Thánatos, as forças apolíneas e as forças dionisíacas, as luzes e as escuridões que tangenciam a irrupção do acontecer verbal, em um intenso jogo feito de tessituras e silêncios. Dessa maneira, o poema-cria assume os matizes de uma escrita convulsiva em contínuos estilhaçamento e transgressão dos limites, como se pode observar nos seguintes versos de "Amavisse":

Tomar para o meu peito a vastidão

O caminho dos ventos

O descomedimento da cantiga

(HILST, 2004, p. 59).

Ao colocar em cena o "descomedimento da cantiga", a linguagem é dramatizada em toda a sua explosão voluptuosa, não somente de 
formas, como também de vida. Significativamente, os versos de "Via espessa" aludem à inclinação do processo criativo ao estado dionisíaco, responsável pelo êxtase, pelo delírio, pela embriaguez, pelo fervor descomedido, pelo desejo passional:

Perco meu passo nos caminhos de terra

E de Dionísio sigo a carne, a ebriedade.

Se te pertenço perco a luz e o nome

E a nitidez do olhar de todos os começos

(HILST, 2004, p. 66).

A criação da obra de arte repete o ato cosmogônico, que, ao encenar a reunião de forças ao mesmo tempo antagônicas e coexistentes, faz convergir os extremos: Apolo e Dionísio, a lucidez e o gozo, a sensatez e a loucura, a claridade e a escuridão. $O$ operar da poesia se inter-relaciona, por um lado, com a festa dionisíaca na celebração da "carne" e da "ebriedade", alimentando-se de uma energia erótica, por excelência. Mas convoca, como seu complemento indispensável, o signo apolíneo que aspira à "luz" e ao "nome" para conceber o gesto de criação. Combinando essas duas instâncias, é possível chegar ao cerne da realização do Eros criativo, do poder criador humano, da vida que pulsa em cada corpo.

Em suma, a parelha escuridão e claridade perpassa fundamentalmente toda a obra hilstiana como uma figuração da dinâmica cosmogônica da criação na circularidade essencial do acontecer poético. Aquele que se aventura nos caminhos da escrita entrega-se a uma cegueira lúcida e impulsiona a passagem do "semnome" à palavra, da obscuridade do ininteligível à clareza do conhecimento, de modo que penetra nos enigmas do mundo e no indecifrável do ser humano. Os versos seguintes do poema já citado, 
"Iniciação do poeta", de Trajetória poética do ser, sintetizam muito bem essa visão:

Estou no centro escuro de todas as coisas

Mas a visão é larga

Como um grito que se abrisse e abrangesse o mar.

(HILST, 1980, p. 185).

Como um iniciado em sua profissão de fé, como "pastor e guardião" da palavra a ser revelada, o poeta experimenta a radicalidade dos limites ao transgredir o "centro escuro de todas as coisas", os arcanos misteriosos da criação, o limiar silencioso diante do qual a palavra encontra resistência, e alcança a liberdade plena de entregarse à imensidão do vir a conhecer, à abertura prodigiosa para o voo livre do Pássaro-Poesia, à vastidão límpida e copiosa do verbo-grito, ao nascimento da palavra mais viva: a poesia.

\section{Considerações finais}

No deflagrar da "urna primitiva das palavras", com o seu poder de dizer e de calar, a obra de Hilda Hilst revela a vigência da sua escrita, à luz de uma cosmogonia poética, como metáfora para o processo criativo. O poema "Amavisse" atualiza a noção de cosmogonia ao instituir a unidade entre a dimensão criativa do corpo e da palavra, de modo que tenciona as esferas do sagrado e do profano, do divino e do humano, do eterno e do efêmero, da poesia e da existência. Arrebatado pela experiência desmedida e desordenada de Eros, o grande corpo da poesia é fecundado na carnalidade visceral da noite para o vir à tona do "poema pulsante". Sob o traço erótico da 
transgressão, o ser criador viola o segredo dos "noturnos desvãos" até trazer a lume a palavra e a centelha dos sentidos.

A partir do operar demiúrgico dessa escrita cosmogônica, eis que o desejo se faz luz: nasce o canto, o poema-cria. Este atravessa o imponderável, a massa caótica do informe, as zonas escuras do sem nome, o núcleo fundante pulsando em silêncio, o fundo desconhecido das coisas para o qual a dimensão do dizer não dispõe de correspondência, em direção ao ventre radiante e fecundo do verbo, à ordem luzente das formas, ao advento rutilante do nome, à transparência resplandecente dos significados. Nessa dialética constante entre a escuridão e a claridade, o dionisíaco e o apolíneo, a cegueira e a lucidez, a cosmogonia poética hilstiana abre-se à possibilidade de experimentar a paixão violenta da linguagem, de testar os limites da própria palavra, de cultivar o fascínio pelo abismo irredutível e inesgotável pertencente ao domínio da criação literária.

Diante disso, o desafio da tarefa de escrever reside no estilhaçamento das estruturas rígidas e opacas da língua para se recompor originalmente no vir a ser de novos corpos verbais. Em meio à corrente vertiginosa da linguagem, ao turbilhão verbal, a palavra toma forma, ou melhor, encarna o seu sopro de vida. Palavra e vida são experiências cosmogônicas instauradoras de realidades de sentido, as quais fundam ontologicamente a unidade primordial do mundo: a palavra poética. A cada nova palavra que é anunciada, a cada nova vida que é gerada, a embocadura da noite renova-se na gestação do canto que repousa no ventre pungente da criação:

E o mais fundo de mim

Me diz apenas: Canta,

Porque à tua volta

É noite. O ser descansa. 
Ousa. $^{24}$

\section{Referências}

ALIGHIERI, Dante. A divina comédia. Tradução, comentários e notas de Italo Eugenio Mauro. Prefácio de Otto Maria Carpeaux. São Paulo: Editora 34, 2009.

ANDRADE, Carlos Drummond de. Antologia poética. Rio de Janeiro: Record, 2000.

BATAILLE, Georges. O erotismo. Tradução de Antonio Carlos Viana. Porto Alegre: L\&PM, 1987.

BÍBLIA. Português. Bíblia Sagrada. Tradução de Antônio Pereira de Figueiredo. São Paulo: Sivadi Editorial, 2010. 1102 p.

COELHO, Nelly Novaes. A poesia obscura/luminosa de Hilda Hilst e a "metamorfose" de nossa época. In: HILST, Hilda. Poesia: 19591979. São Paulo: Quíron; Brasília: INL, 1980.

. Da poesia. Cadernos de literatura brasileira. São Paulo, Instituto Moreira Salles, n. 8, out. 1999.

ELIADE, Mircea. Mito e realidade. Tradução de Pola Civelli. São Paulo: Perspectiva, 1972.

HILST, Hilda. Poesia: 1959-1979. São Paulo: Quíron; Brasília: INL, 1980. A obscena senhora D. São Paulo: Globo, 2001. . Do desejo. São Paulo: Globo, 2004.

LESBOS, Safo de. Poemas e fragmentos. Tradução de Joaquim Brasil Fontes. São Paulo: Iluminuras, 2003.

${ }^{24}$ Versos finais do poema "Exercício no 1", pertencente à obra Exercícios para uma ideia (1967), de Hilda Hilst (HILST, 1980, p. 135).

Revista Texto Poético I ISSN: 1808-5385 | Vol. 20 (1o sem-2016) - p. 187 
MORAES, Eliane Robert. Da medida estilhaçada. Cadernos de literatura brasileira. São Paulo, Instituto Moreira Salles, n. 8, out. 1999.

NUNES, Benedito. Introdução à fillosofia da arte. 5. ed. 4. reimp. São Paulo: Ática, 2003.

PAES, José Paulo. Poesia erótica em tradução. Seleção, tradução, introdução e notas de José Paulo Paes. São Paulo: Companhia das Letras, 2006.

PAZ, Octavio. A dupla chama: amor e erotismo. Tradução de Wladir Dupont. 2. ed. São Paulo: Siciliano, 1994. 